ARTICLE

https://doi.org/10.1038/s41467-020-16283-9

\title{
OPEN
}

\section{Alkyne-Alkene [2 + 2] cycloaddition based on visible light photocatalysis}

\author{
Sujin Ha (1) ${ }^{1}$, Yeji Lee (1) ${ }^{1}$, Yoonna Kwak (1) ${ }^{1}$, Akash Mishra (i) ${ }^{1}$, Eunsoo Yu (i) ${ }^{1}$, Bokyeong Ryou (1) ${ }^{1}$ \& \\ Cheol-Min Park (iD ${ }^{1 凶}$
}

UV-activated alkyne-alkene [2 +2$]$ cycloaddition has served as an important tool to access cyclobutenes. Although broadly adopted, the limitations with UV light as an energy source prompted us to explore an alternative method. Here we report alkyne-alkene [2+2] cycloaddition based on visible light photocatalysis allowing the synthesis of diverse cyclobutenes and 1,3-dienes via inter- and intramolecular reactions. Extensive mechanistic studies suggest that the localized spin densities at $s p^{2}$ carbons of alkenes account for the productive sensitization of alkenes despite their similar triplet levels of alkenes and alkynes. Moreover, the efficient formation of 1,3-dienes via tandem triplet activation of the resulting cyclobutenes is observed when intramolecular enyne cycloaddition is performed, which may serve as a complementary means to the Ru(II)-catalyzed enyne metathesis. In addition, the utility of the $[2+2]$ cycloaddition has been demonstrated by several synthetic transformations including synthesis of various extended $\pi$-systems.

\footnotetext{
${ }^{1}$ Department of Chemistry, UNIST (Ulsan National Institute of Science \& Technology), Ulsan 44919, Korea. ${ }^{凶}$ email: cmpark@unist.ac.kr
} 
T he synthesis of cyclobutenes has drawn much attention from the synthetic community owing to their versatility as synthetic intermediates and their presence in complex natural products ${ }^{1}$. Since thermal $[2+2]$ cycloaddition of alkynes with alkenes is a thermally forbidden process, the synthesis of cyclobutenes has been developed primarily based on direct excitation by UV light (Fig. 1a) ${ }^{2-6}$. Recently, a chiral UV sensitizer has been reported for enantioselective synthesis of cyclobutenes ${ }^{7}$. On the other hand, various alternative methods including Lewis acid-8-11 and transition metal- ${ }^{-12-16}$ catalyzed syntheses of cyclobutenes have been developed. However, the requirement of specific functional groups on the substrates for activation remains as limitation.

The past decade has seen a surge of developments in visiblelight photocatalysis ${ }^{17-20}$. A number of elegant syntheses have been reported based on electron transfer (ET) photoredox processes $^{21-26}$. Meanwhile, energy transfer (EnT) processes have drawn attention as an alternative visible-light photocatalysis in an increasing number of transformations ${ }^{27-29}$. For example, synthesis of N-heterocycles via sensitization of azido compounds ${ }^{30-35}$ and isomerization of alkenes ${ }^{36-38}$ have been described. Also, alkene-alkene $[2+2]$ cycloaddition for the synthesis of cyclobutanes in inter- and intramolecular fashion based on the EnT process has been reported ${ }^{39-46}$. Meanwhile, only a limited number of studies on the alkyne-alkene reactions with visible light photocatalysis have been reported. Very recently, Glorius ${ }^{47}$

\section{a Previous works \\ Cyclobutenes via [2+2] cycloaddition

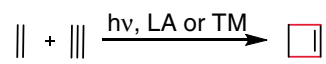 \\ Photochemical reaction (UV light) \\ Lewis acid (LA)-catalyzed reaction \\ Transition metal (TM)-catalyzed reaction}

Cyclobutanes via visible light photocatalysis

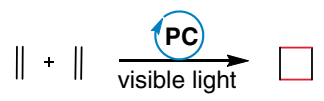

Electron transfer

Energy transfer

Ring-closing enyne metathesis

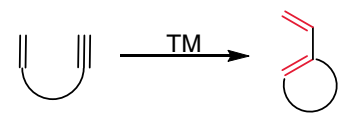

Ru-catalyzed reaction (limited substitution on enynes)

\section{b This work}

Visible light photocatalysis based on energy transfer process

- Cyclobutenes via [2+2] cyloaddition

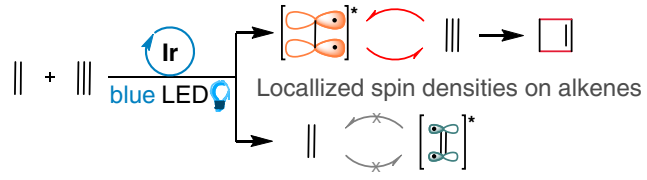

- Formal enyne metathesis (highly substituted enynes)

- Tandem triplet activation

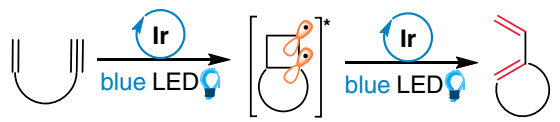

Fig. 1 Synthesis of 4-membered ring carbocycles. a Previous works for the synthesis of cyclobutenes, cyclobutanes, and 1,3-dienes. b This work for the synthesis of cyclobutenes and 1,3-dienes via visible light EnT photocatalysis. and $\mathrm{Maestri}^{48}$ groups described novel alkyne-alkene reactions under visible light photocatalysis.

1,3-Dienes are a valuable synthetic moiety that are found in a wide variety of transformations. Intense research efforts have been made to develop efficient synthesis. For example, a number of elegant synthesis 1,3-dienes based on transition metal-catalysis including gold $^{49-51}$, palladium ${ }^{52,53}$, and platinum ${ }^{54,55}$. Also, enyne metathesis with Grubbs catalysts has proven to be an efficient method for the synthesis of various 1,3-dienes ${ }^{56,57}$. Meanwhile, direct access to 1,3-dienes from enynes based on visible-light photocatalysis would offer a complementary route to enyne metathesis.

Here we report the visible light EnT-based alkyne-alkene [2+ 2] cycloaddition, which displays an intriguing dichotomy in reactivity with respect to the types of substrates (Fig. 1b). Whereas the intermolecular reaction affords cyclobutenes, the formation of 1,3-dienes in the case of intramolecular reaction is remarkable.

\section{Results}

Reaction optimization. We began the screening with various photocatalysts under visible-light irradiation by employing $\operatorname{di}(p$ tolyl)acetylene $\mathbf{1 a}$ and $N$-methylmaleimide $\mathbf{2} \mathbf{a}$ as the coupling partners (see Supplementary Table 1). It turned out that the use of $2.5 \mathrm{~mol} \% \operatorname{Ir}\left[\mathrm{dF}\left(\mathrm{CF}_{3}\right) \text { ppy }\right]_{2}$ (dtbbpy) $\mathrm{PF}_{6}$ (PC I) was optimal to afford 3aa in $83 \%$ yield. Moreover, the cycloaddition proceeded with higher yields in nonpolar solvents under diluted concentration $\left(\mathrm{CH}_{2} \mathrm{Cl}_{2}\right.$ in $\left.0.05 \mathrm{M}\right)$. To confirm that the reaction is driven by photocatalysis, control reactions were performed, in which no reaction was observed in the absence of light or a catalyst.

At this juncture, we were prompted to investigate the underlying factors governing the reactivity of the catalysts observed during the screening (Table 1). To distinguish the two plausible reaction pathways, $\mathrm{ET}$ and $\mathrm{EnT}$, the reduction potential $\left(E_{\mathrm{p} / 2}{ }^{\mathrm{red}}=\right.$ $-1.16 \mathrm{~V}$ vs. SCE) and triplet energy $(55.9 \mathrm{kcal} / \mathrm{mol})$ of $N$ methylmaleimide $2 \mathrm{a}$ were compared with those of the catalysts. A clear correlation was observed between the yields of the cycloadduct and the triplet energies of the catalysts, while their reduction potentials are inconsistent with the conversions of the reaction. For example, PC I, which has the highest triplet energy $(60.8 \mathrm{kcal} / \mathrm{mol})$, turned out to be the most efficient for cycloaddition, however, its reduction potential $\left(E_{1 / 2}\left(\mathrm{M}^{*} / \mathrm{M}^{+}\right)=-0.89 \mathrm{~V}\right.$ vs. SCE) is insufficient for the reduction of 2a. On the other hand, a trace conversion was observed with the catalyst PC VI, which has a slightly higher reduction potential $\left(E_{1 / 2}\left(\mathrm{M}^{*} / \mathrm{M}^{+}\right)=-0.96 \mathrm{~V}\right.$ vs. SCE) but much lower triplet energy $(49.2 \mathrm{kcal} / \mathrm{mol})$ than that of 2a. Likewise, the same trend was observed for alkyne $\mathbf{1 a}\left(E_{\mathrm{p} / 2}{ }^{\text {red }}=\right.$ $-2.5 \mathrm{~V}, E_{\mathrm{p} / 2}$ ox $=+1.59 \mathrm{~V}$ vs. SCE and $\left.E_{\mathrm{T}}=56.7 \mathrm{kcal} / \mathrm{mol}\right)$, in which the yields showed good correlation with the triplet energies rather than the redox potentials of the catalysts. These observations led us to propose that EnT process is in operation for the alkyne-alkene [2+2] cycloaddition, although it remains unclear which counterpart between alkenes and alkynes undergoes productive triplet excitation.

Substrate scope. With the optimized conditions in hand, we investigated the scope of the intermolecular reaction. First, we examined the steric and electronic influences of substituted diarylalkynes by reacting with $N$-methylmaleimide $2 \mathbf{a}$. It was found that both electron-rich and deficient alkynes were well tolerated (Fig. 2, 3aa-3ha). The utility of heterocycles in bioactive compounds prompted us to examine pyridine- and pyrazinesubstituted alkynes ${ }^{58}$. We were gratified to find that these heterocyclic substrates reacted smoothly to afford the corresponding 


\section{Table 1 Triplet energies and redox potentials of photocatalystsa.}
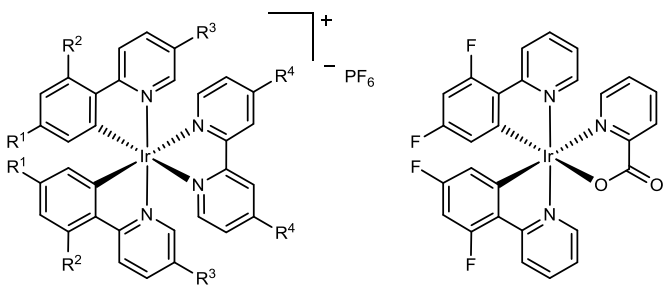

PC I $R^{1}=F, R^{2}=F, R^{3}=C_{3}, R^{4}={ }^{t} B u$

PC III $R^{1}=F, R^{2}=F, R^{3}=C_{3}, R^{4}=H$

PC IV $R^{1}=F, R^{2}=F, R^{3}=H, R^{4}={ }^{t} B u$

$P C \vee R^{1}=F, R^{2}=H, R^{3}=H, R^{4}={ }^{t} B u$

PC VI $R^{1}=H, R^{2}=H, R^{3}=H, R^{4}={ }^{t_{B}} \mathrm{Bu}$

PC II

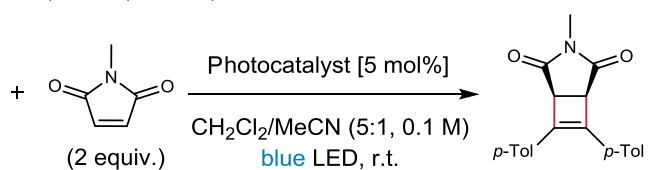

$1 \mathrm{a}$

2a

3aa

\begin{tabular}{|c|c|c|c|c|}
\hline Entry & Photocatalyst & $E_{1 / 2}\left(M^{\star} / M^{+}\right) / E_{1 / 2}\left(M^{\star} / M^{-}\right)(V$ vs SCE $)$ & $E_{\mathrm{T}}(\mathrm{kcal} / \mathrm{mol})$ & Yieldb \\
\hline$\overline{1 c}$ & PC I & $-0.89 /+1.21$ & 60.8 & $83 \%$ \\
\hline $2^{d}$ & PC I & $-0.89 /+1.21$ & 60.8 & $75 \%$ \\
\hline 3 & PC ॥ & $-1.23 /+1.40$ & 60.5 & $74 \%$ \\
\hline 5 & PC IV & $-0.93 /+1.14$ & 55.4 & $62 \%$ \\
\hline 6 & PC V & $-1.04 /+1.07$ & 53.0 & $35 \%$ \\
\hline 7 & PC VI & $-0.96 /+0.66$ & 49.2 & trace \\
\hline
\end{tabular}

aReactions were performed with $0.05 \mathrm{mmol}$ scale under Ar. Racemate for 3aa. $p$-Tol $=p$-tolyl, bpy $=2,2^{\prime}$-bipyridine, n.r. $=$ no reaction

bYields determined by ${ }^{1} \mathrm{H}$ NMR spectroscopic analysis against an internal standard. (1,1,2-trichloroethene).

cReaction was performed with 1.5 equiv. of $\mathbf{2 a}$ and $2.5 \mathrm{~mol} \%$ of $\mathbf{P C} \mathbf{I}$ in $\mathrm{CH}_{2} \mathrm{Cl}_{2}(0.05 \mathrm{M})$.

dReaction was performed with 1.5 equiv. of $\mathbf{2 a}$ and $1.0 \mathrm{~mol} \%$ of $\mathbf{P C} \mathbf{I}$ in $\mathrm{CH}_{2} \mathrm{Cl}_{2}(0.05 \mathrm{M})$.

eGreen LED instead of blue LED.

cyclobutenes in good yields (3ia-3ka). Furthermore, the reaction of alkyne $\mathbf{1 1}$ bearing a cyclopropyl group gave 31 a in $67 \%$ yield with the cyclopropyl ring intact.

In addition to the aryl substitution, alkynes substituted with alkyl groups were also examined. We were pleased to find that the reaction with dialkylalkynes $\mathbf{1 m}$ and $\mathbf{1 n}$ proceeded to afford the corresponding cyclobutenes $3 \mathbf{m a}$ and 3 na. Moreover, both silylsubstituted and terminal alkynes 1o-1u smoothly participated in the reaction. We were also intrigued whether the reaction would tolerate substrates with free hydroxyl and carboxylic acid groups, which would allow obviating protecting group chemistry. Indeed, the alkynes $1 \mathbf{s}$ and $\mathbf{1 u}$ gave cyclobutenes 3si and 3ua in 85 and $78 \%$ yield, respectively. 1,3-Diyne $1 \mathbf{v}$ turned out to be a good substrate to afford the corresponding alkyne-substituted cyclobutene 3va in $70 \%$ yield.

Next, we investigated the reactivity of the alkene counterpart, and found that alkenes flanked by electron-withdrawing groups are required for efficient conversion. Thus, those flanked by the functionalities including anhydride, amide, ester, and nitrile participated smoothly in the reaction (Fig. 2, 3ab-3cg). To examine the detailed electronic and steric impact of maleimide on the cycloaddition, various $N$-substituted maleimides were subjected to the standard conditions. It turned out that both $\mathrm{N}-\mathrm{H}, \mathrm{N}$-alkyl maleimides $\mathbf{2 h}$ and $\mathbf{2 i}$ gave the corresponding cyclobutenes $3 \mathbf{a h}$ and 3ai in excellent yields. Various $N$-substituted maleimides including $\mathrm{N}$-benzyloxy, 4-cyanophenyl, and 4-carbomethoxyphenyl maleimides were tolerated to afford cyclobutenes in good to moderate yields (3aj-3al). In addition, the introduction of N-heteroarenes in the cycloadduct was achieved with the maleimide $\mathbf{2 n}$. The effect of the substitution on the olefinic moiety of maleimide was further investigated. The maleimides 2o-2r bearing bromo, methoxy, and methyl substituents gave the cyclobutenes in excellent yields. Dimethyl substituted maleimide $2 \mathrm{~s}$, however, afforded the corresponding cycloadduct in $55 \%$ yield presumably owing to the steric hindrance. Reaction of $\mathbf{2 t}$ derived from ${ }_{\mathrm{L}}$-alanine successfully proceeded to give 3 at in $93 \%$ yield.

Whereas acyclic alkenes of mono-activation such as cinnamate failed to give the corresponding cyclobutene (3au, see Supplementary Fig. 1a for unreactive alkenes), cyclic mono-activated alkenes including lactam $\mathbf{3 a v}$ and lactones (3aw-3xw) afforded the corresponding products in good to moderate yields. Moreover, a highly sterically hindered product bearing a quaternary center such as 3ax was produced in high yield (76\%). We speculate that the failure of the acyclic alkenes may be attributed to the catalyst quenching owing to the pathway involving $E / Z$ isomerization ${ }^{36-38}$. Meanwhile, the observed reactivity of 1 a with $2 \mathbf{w}$ was compared with that under direct UV-irradiation. It turned out that the reaction was sluggish under both $254 \mathrm{~nm}$ and $365 \mathrm{~nm}$ (17 and 3\%, respectively; see Supplementary Fig. 1b). Also, late stage modification of commercial drugs containing alkynes proceeded smoothly when performed on $O$-acetyl $17 \alpha$-ethynylestradiol and Efavirenz to afford 3ya and 3za in 66 and 45\% yield, respectively.

A successful implementation of intramolecular alkyne-alkene cycloaddition would offer an access to valuable cyclic compounds. 

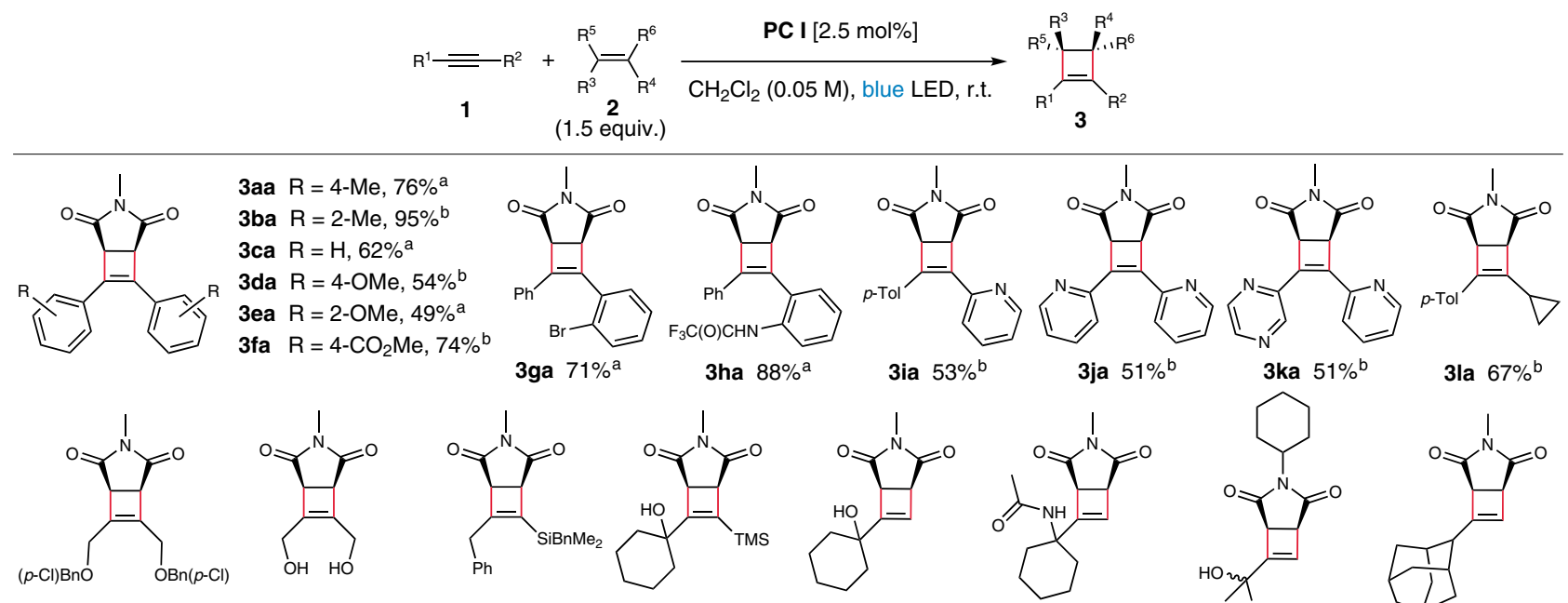

3ma $56 \%^{a}$

3na $91 \%^{a}$

3oa $72 \%^{a}$

3pa $94 \%^{\mathrm{a}}$

3qa $60 \%^{a}$

3ra $98 \%^{a}$
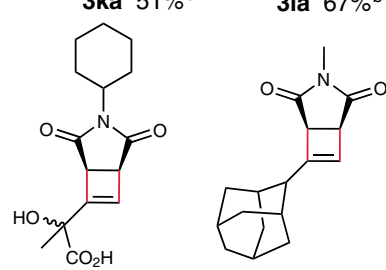

$\ln _{\text {3ua } 78 \% a}^{\text {a }}$
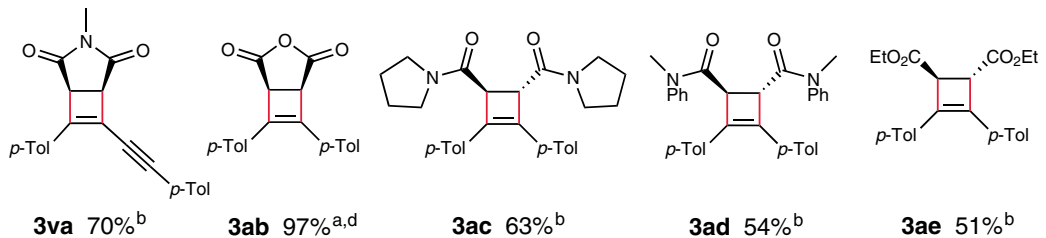

3si $85 \%$

3ta $48 \%^{a}$

(d.r.=1:1)<smiles>CCCC1=C([Te])C2C(=O)N(P)C(=O)C12</smiles>

3ah $\mathrm{R}=\mathrm{H}, 82 \%^{\mathrm{b}}$
3ai $\mathrm{R}=$ Cyclohexyl, $80 \%^{\mathrm{b}}$

3aj $\mathrm{R}=\mathrm{OBn}, 42 \%{ }^{\mathrm{b}}$

3ak $\mathrm{R}=4-\mathrm{CNPh}, 59 \%^{\mathrm{b}}$

3al $\mathrm{R}=4-\mathrm{CO}_{2} \mathrm{MePh}, 46 \%{ }^{\mathrm{b}}$

3am $\mathrm{R}=\mathrm{Ph}, 29 \%^{\mathrm{C}}$

3an $R=3-$ Pyridyl, $55 \%$ b

3ac $63 \%^{\mathrm{b}}$

3ad $54 \%^{\text {b }}$

3ae $51 \%^{\mathrm{b}}$<smiles>[N]C1C([18O])=C(C#C[Te])C1[N]</smiles><smiles>CC(=O)OC1C(c2ccccc2)=C(c2ccccc2)C1C(=O)N[Ga]O[Na]</smiles>

3vf $51 \%^{\mathrm{b}}$

(cis/trans 1.3:1)

3cg $42 \%^{\mathrm{c}}$

(cis/trans 1:5)

(cis/trans 1.3:1)

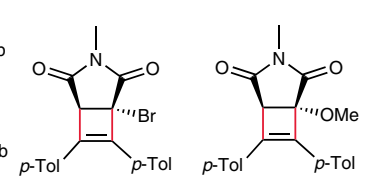

p-Tol

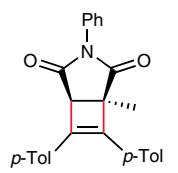

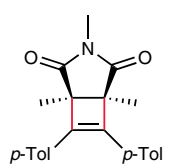<smiles>CC(=O)C(C)NC(=O)C1C([18O])=C([18O])C1C(=O)O</smiles>

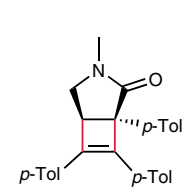<smiles>O=C1Oc2ccccc2C2C([Te])=C([Te])C12</smiles>

3aw $71 \%$ b

3ap $98 \%{ }^{\mathrm{b}}$

3aq $88 \%$ b

3ar $99 \%^{\mathrm{b}}$

3as $55 \%{ }^{\text {b }}$

3at $93 \%^{\mathrm{a}}$

(cis/trans 4.4:1)

3au $0 \%$

3av $43 \%^{\mathrm{c}}$<smiles>CC(=O)OC1C([18O])=C([18O])[C@@H]1c1ccccc1</smiles>

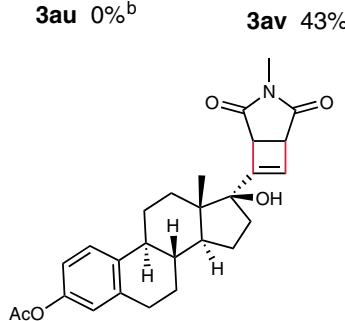

3ya $66 \%^{a}$

(cis, d.r.=1.4:1)<smiles>O=C1Oc2ccccc2C2(c3oc4ccccc4c3[18O])C(=O)Oc3ccccc3C12</smiles>

3ww $92 \%(1.8: 1)^{b}$<smiles>Nc1ccccc1C1=C(c2ccccc2)C2C(=O)Oc3ccccc3C12</smiles>

3xw $68 \%{ }^{\circ}$<smiles>C[C@@]12C([18O])=C([18O])C1C(=O)Oc1cc(O)ccc12</smiles>

3ax $76 \%^{b}$<smiles>CN1C(=O)C2C(C3CC3)=C([C@@]3(C)OC(=O)Nc4ccc(Cl)cc43)C2C1=O</smiles>

3za $45 \%$

(cis, d.r.=2.3:1)

Fig. 2 Scope of the intermolecular reaction. Unless noted otherwise, all reactions were conducted with 0.1 mmol scale under irradiation of $12 \mathrm{~W}$ blue LED strip and Ar atmosphere; Isolated yields; Racemates for all cyclobutenes. ${ }^{a}$ Reaction time: 1-18 h. ${ }^{b}$ Reaction time: $24-48 \mathrm{~h}$. ${ }^{\mathrm{c}}$ Reaction time: $53 \mathrm{~h}-3 \mathrm{~d}$. ${ }^{\mathrm{d}}$

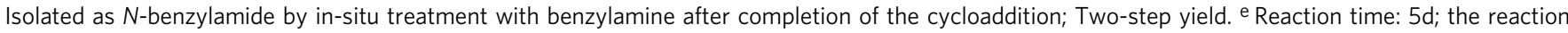
was conducted with 15 equiv. of alkene and PC III instead of PC I.

When the ester-tethered enyne $\mathbf{4 a}$ was subjected to the optimized reaction conditions, coumarin $\mathbf{6 a}$ was obtained in $73 \%$ yield $(E / Z=1: 1)$ (Fig. 3). While the formation of diene $6 \mathbf{a}$ was unexpected, we speculated that ring opening of the initial cyclobutene accounts for the diene formation. Also, the control experiments without light or photocatalyst showed no reaction (see Supplementary Fig. 2a). Thus, the photocatalyzed intramolecular enyne cycloaddition allows an access to highly substituted 1,3-dienes readily built from simple enyne substrates, which serves as a complementary means to the enyne metathesis. Interestingly, among the ample literature precedents, the syntheses of these highly substituted 1,3-dienes based on enyne metathesis are scarce with necessitating terminal alkenes. As such, a comparison was performed by using 4 a (see Supplementary Fig. 2b). Whereas the $[2+2]$ cycloaddition gave $\mathbf{6 a}$ in $73 \%$ yield, enyne metathesis failed to give $\mathbf{6 a}$.

The examination of the scope of the alkyne substituents revealed broad tolerability (Fig. 3). Those substituted with aryl 


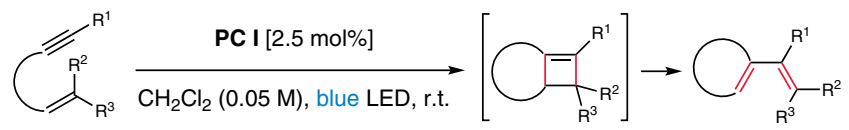

5

Substrate

$4 a$<smiles>CS(C)(=O)(O)C#Cc1ccccc1OC(=O)/C=C/[Te]</smiles>

$4 b$<smiles>[R7]c1ccc(C#Cc2ccccc2N(P)C(=O)/C=C/c2cccc(Pn3c(=O)cc(/C(=C/c4ccccc4)c4ccc([Te])cc4)c4ccccc43)c2)cc1</smiles>

4c, $4 d, 4 e \quad 6 c R^{4}=M e, R^{5}=E t, R^{6}=4-M e$ $80 \% \mathrm{a}(E / Z=2: 1)$

6d $\mathrm{R}^{4}=\mathrm{H}, \mathrm{R}^{5}=\mathrm{Et}, \mathrm{R}^{6}=2-\mathrm{Br}$ $74 \%{ }^{\mathrm{b}}(E / Z=1.8: 1)$

$6 e \mathrm{R}^{4}=\mathrm{Me}, \mathrm{R}^{5}=\mathrm{Ph}, \mathrm{R}^{6}=4-\mathrm{Me}$ $95 \%{ }^{\mathrm{a}}(E / Z=1.5: 1)$<smiles>CCNc1ccccc1C#Cc1ccccn1</smiles>

$4 f$<smiles>O=C(/C=C/[Pb])Nc1ccccc1C#Cc1cncc2ccccc12</smiles>

$4 \mathrm{~g}$<smiles>CCc1ccccc1C#CC(=O)/C=C/[Pb]</smiles>

4h

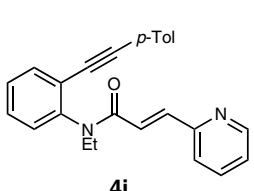

$4 \mathbf{i}$
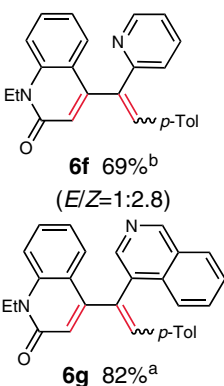

$(E / Z=1.5: 1)$

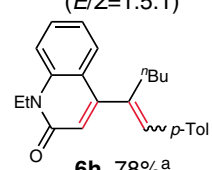

$(E / Z=1.7: 1)$

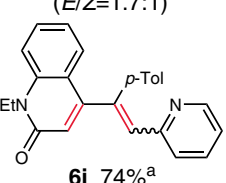

$(E / Z=1.3: 1)$<smiles>CCNc1ccccc1C#CC(=O)/C=C/c1ccco1</smiles>

4j

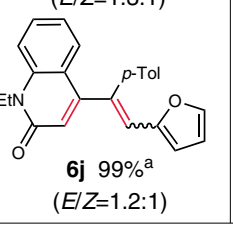

Product

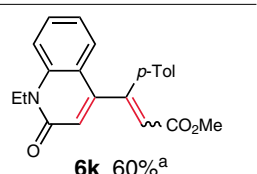

6k $60 \%{ }^{\mathrm{a}}$

$(E / Z=1.5: 1)$

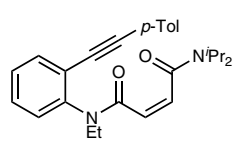

41

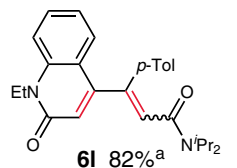

$(E / Z=1: 2.4)$<smiles>CCc1ccccc1C#C[Te]</smiles>

$4 \mathrm{~m}$

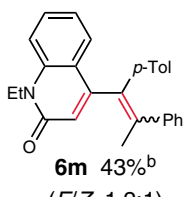

$(E / Z=1.2: 1)$

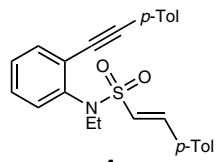

$4 n$<smiles>O=[PH](=O)(O)OCC=CC(=C[Te])C1=CS(=O)(=O)Nc2ccccc21</smiles>

$(E / Z=1.3: 1)$
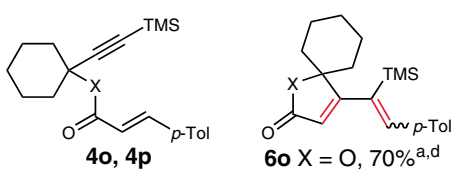

$60 X=0,70 \%^{a, d}$

$(E / Z=1: 1)$

$6 \mathrm{p} X=\mathrm{NPh}, 60 \%^{\mathrm{b}}$

(only Z)

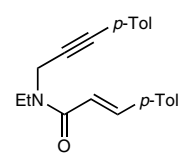

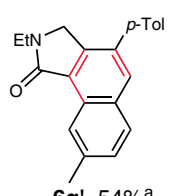

$4 q$

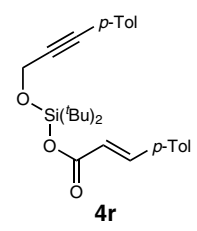<smiles>CC(C)(C)[Al]1OCC2=C([18O])[C@@H]([18O])[C@H]2C(=O)O1</smiles>

5r $62 \%{ }^{c}$

Fig. 3 Scope of the intramolecular reaction. Unless noted otherwise, all reactions were conducted in $0.1 \mathrm{mmol}$ scale under irradiation of $12 \mathrm{~W}$ blue LED strip and Ar atmosphere; Isolated yields. ${ }^{a}$ Reaction time: $1-18 \mathrm{~h} .{ }^{\mathrm{b}}$ Reaction time: $24-48 \mathrm{~h} .{ }^{\mathrm{c}}$ Reaction time: $60 \mathrm{~h}$, racemate for $\mathbf{5 r}$. ${ }^{\mathrm{d}}$ Reaction was conducted with $0.05 \mathrm{mmol}$ scale; Reaction concentration: $0.01 \mathrm{M}$. 


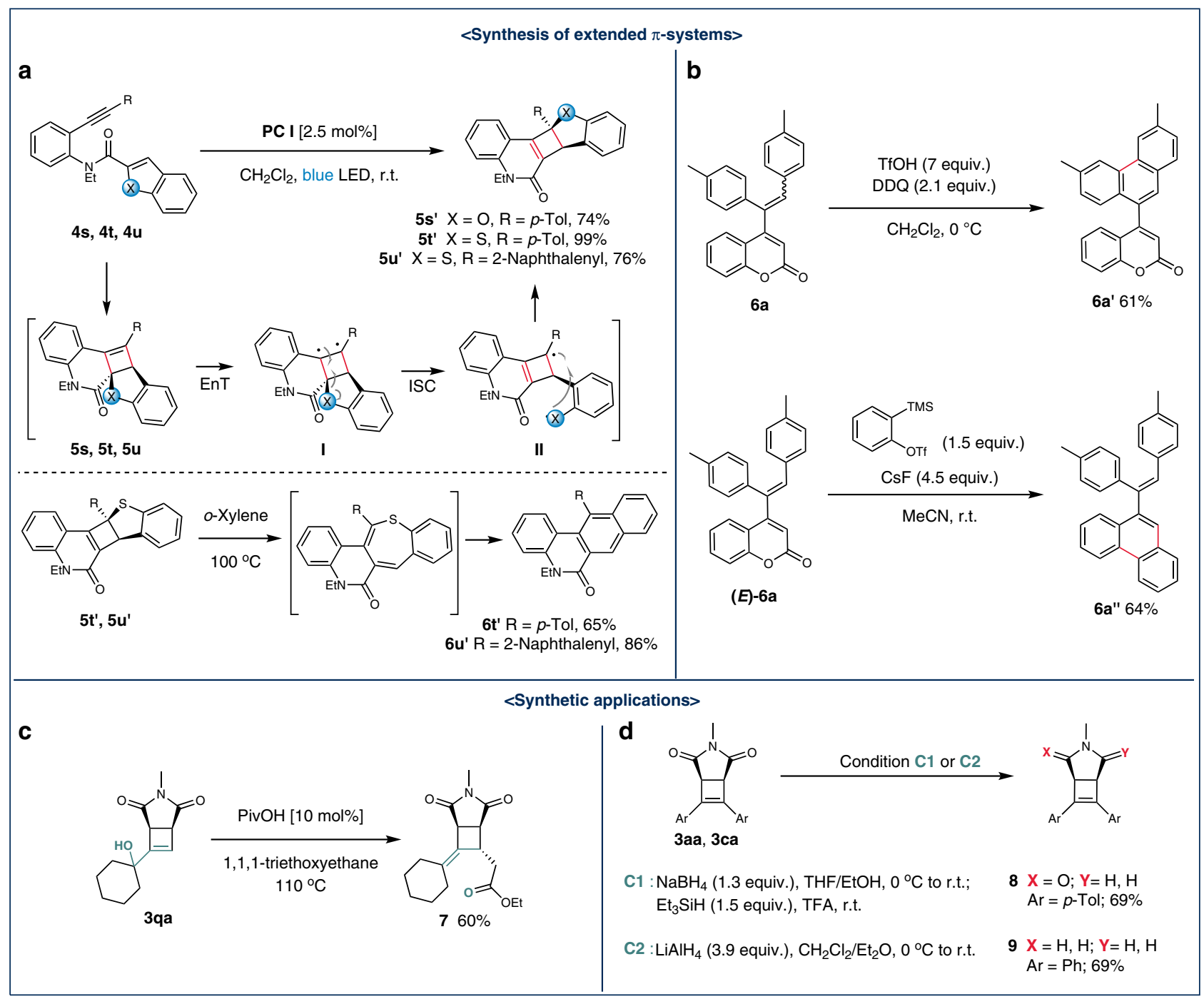

Fig. 4 Synthesis of extended $\boldsymbol{\pi}$-systems and synthetic applications. Racemates for all cyclobutenes. a Tandem cycloaddition followed by rearrangement of benzofuran and benzothiophenes. (ISC = Intersystem crossing). b Derivatization of coumarin. (DDQ = 2,3-dichloro-5,6-dicyano-1,4-benzoquinone). c Synthesis of exomethylene cyclobutene. $\mathbf{d}$ Synthesis of $\gamma$-lactam and pyrrolidine derivatives.

and TMS groups gave the corresponding coumarins in good yields (6a and $\mathbf{6 b}$ ). Likewise, 2-quinolones $\mathbf{6 c - 6 e}$ could be synthesized in good to excellent yields by employing amido tethers. Alkynes substituted with various types of substituents including aryl, heteroaryl, and alkyl groups reacted smoothly to give the corresponding 2-quinolones. For example, heteroarylsubstituted 2-quinolones $\mathbf{6 f}$ and $\mathbf{6 g}$ were readily prepared by employing alkynes bearing pyridine and isoquinoline groups, respectively. Also, substitution of the alkene moiety with various groups including pyridine, furan, ester, and amide was well tolerated $(\mathbf{6 i}-\mathbf{6} \mathbf{l})$.

The effect of steric hindrance on the alkene moiety was examined with the substrate $\mathbf{4 m}$ bearing a trisubstituted alkene, which gave $\mathbf{6 m}$ in albeit moderate yield. In addition to amido tethers, sulfonamide also turned out to be an effective tether providing a cyclic sulfonamide $\mathbf{6 n}$. Lastly, we examined the feasibility of 5-membered ring formation with ester and amidotethered substrates afforded the corresponding unsaturated lactone 60 and lactam $\mathbf{6 p}$ in 70 and $60 \%$, respectively. Interestingly, the reaction with $\mathbf{4 q}$ furnished $\mathbf{6} \mathbf{q}^{\prime}$ via electrocyclization of the corresponding diene. When silyl-tethered $\mathbf{4 r}$ was subjected to the reaction conditions, cyclobutene-fused 7membered ring product $\mathbf{5 r}$ was obtained in $62 \%$ yield.
Synthetic applications. Extended $\pi$-systems are an important feature in various applications including fluorescence sensors and material science ${ }^{59-62}$. As such, we explored the accessibility to such systems based on our synthetic method (Fig. 4a, b). When we performed an intramolecular $[2+2]$ cycloaddition with enyne 4s containing benzofuran as an alkene counterpart, an unexpected product was obtained in $74 \%$, whose structure was assigned as $\mathbf{5} \mathbf{s}^{\prime}$ (see Supplementary Figs. 346 and 347). This is in contrast to the diene formation observed in other intramolecular enynes lacking heterocyclic substituents, which arises from the ring opening of cyclobutenes. The rearrangement could be explained by that excitation of the cyclobutene intermediate $5 \mathrm{~s}$ leads to the formation of 1,2-diradical I, which undergoes fragmentation to give 1,5-diradical II followed by recombination to give $5 \mathbf{s}^{\prime}$. This rearrangement turned out to be quite general in that the benzothiophene derivatives $\mathbf{4 t}$ and $\mathbf{4} \mathbf{u}$ afforded $\mathbf{5} \mathbf{t}^{\prime}$ and $\mathbf{5} \mathbf{u}^{\prime}$ in 99 and $76 \%$, respectively.

To promote ring expansion, $5 \mathbf{t}^{\prime}$ was heated at $100^{\circ} \mathrm{C}$. Gratifyingly, tetracyclic compound $\mathbf{6 t}^{\prime}$ was obtained in $65 \%$ yield, which could be rationalized by the thermal electrocyclic ring opening followed by sulfur extrusion. Also, the ring expansion reaction with $\mathbf{5} \mathbf{u}^{\prime}$ proceeded well to give the rearrangement product $\mathbf{6} \mathbf{u}^{\prime}$ in $86 \%$ yield upon thermolysis. Also, 
we showed that different phenanthrenes $\mathbf{6} \mathbf{a}^{\prime}$ and $\mathbf{6} \mathbf{a}^{\prime \prime}$ could be readily prepared from $\mathbf{6 a}$ by oxidative cyclization and benzyne cycloaddition, respectively.

The synthetic utility of cyclobutenes were further illustrated by the several transformations (Fig. 4c, d). Exomethylene cyclobutane 7 was prepared from allylic alcohol 3qa by Johnson-Claisen rearrangement. In addition, 2-pyrrolidone and pyrrolidine could be synthesized in good yields by the reduction of cyclobutenes 3aa and 3ca bearing maleimide.

Mechanistic studies. To determine whether the reaction involves a radical chain mechanism, we performed light on-off experiments on both inter- and intra-molecular reactions (3ca and $\mathbf{6 d}$, respectively, see Supplementary Fig. 4). Conversions stopped in the absence of light in both experiments, which rules out a radical chain mechanism. This result was further confirmed by measuring the quantum yield of the cycloaddition of $\mathbf{1 a}$ and $\mathbf{2 a}$. The value of 0.91 strongly supports that the cycloaddition is a nonchain reaction (see Supplementary Discussion). To further corroborate that the EnT process is operative in the cycloaddition, we performed an experiment in the presence of triplet quencher benzil $\left(E_{\mathrm{T}}=53.4 \mathrm{kcal} / \mathrm{mol}\right)$, and found that the yield significantly decreased to $30 \%$. (Fig. 5a).

Next, Stern-Volmer quenching experiments on several catalysts were performed by employing $1 \mathbf{a}$ and $\mathbf{2} \mathbf{a}$ as the quenchers to examine the correlation between the extent of quenching and triplet energy or redox potential (see Supplementary Figs. 7-9). The degree of quenching among the catalysts by $\mathbf{1 a}$ was in good agreement with their triplet energies, not with their redox potentials, in which PC I with the highest triplet energy displays the most significant quenching. Likewise, the same propensity was observed with $\mathbf{2 a}$, albeit the extent of quenching was less efficient compared to 1a. These results suggest that the cycloaddition is promoted via EnT.
An ensuing question was which counterpart between the alkyne and alkene undergoes productive triplet excitation, given their similar triplet energies (1a $56.7 \mathrm{kcal} / \mathrm{mol}$ vs. 2a $55.9 \mathrm{kcal} / \mathrm{mol}$ ). The analysis of the Stern-Volmer experiments indicates that 1a is a much more efficient quencher compared to $\mathbf{2 a}$, which may suggest that alkynes excited to the triplet state react with the ground state alkenes. On the contrary, no queching of PC I by alkyne $1 \mathbf{m}$ was observed, which possesses much higher triplet energy
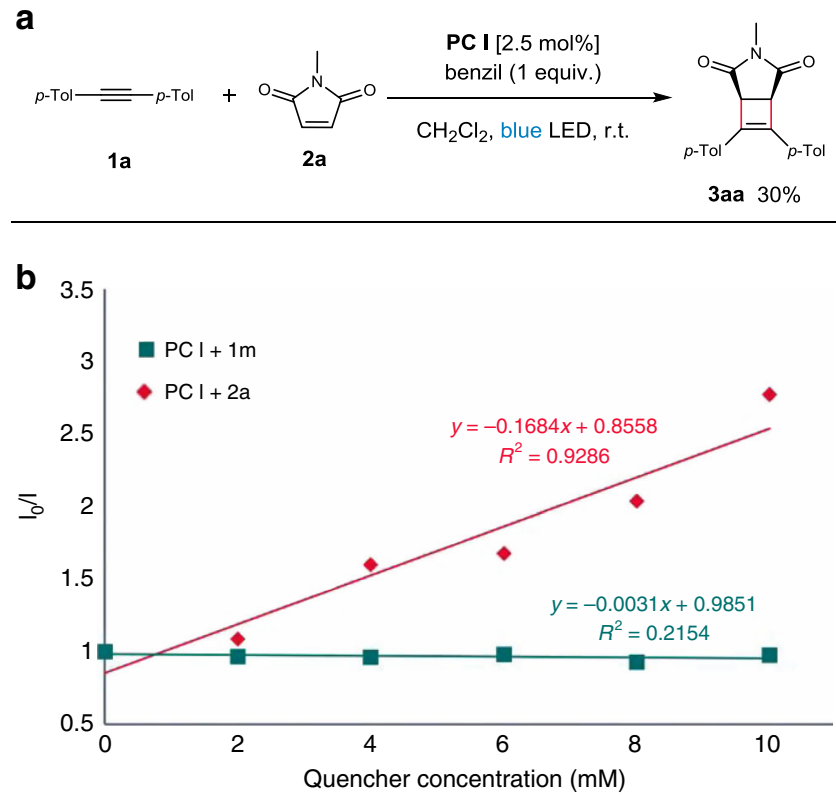

Fig. 5 Mechanistic studies. a Effect of triplet quencher. b Stern-Volmer luminescence quenching experiments using a $0.1 \mathrm{mM}$ solution of $\mathbf{P C} \mathbf{I}$ and variable concentrations of substrate $\mathbf{1 m}$ and $\mathbf{2 a}$ in $\mathrm{CH}_{2} \mathrm{Cl}_{2}$.

a

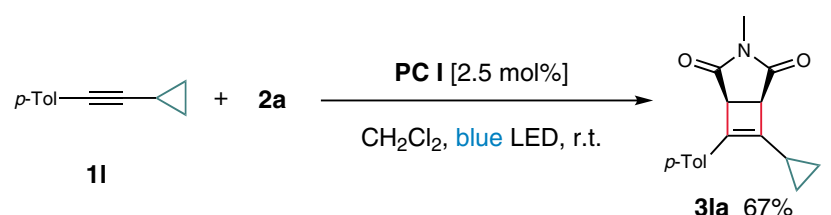

3la $67 \%$

b

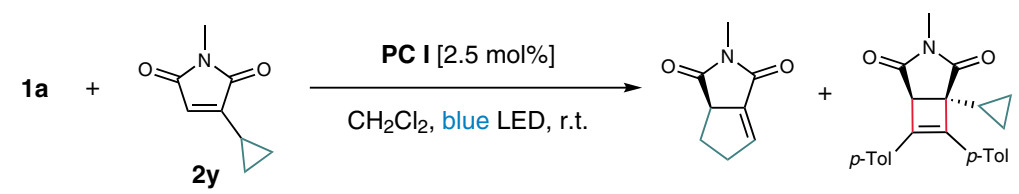

$2 \mathbf{y}^{\prime} \mathbf{1 7 \%} \quad$ 3ay $19 \%$

C
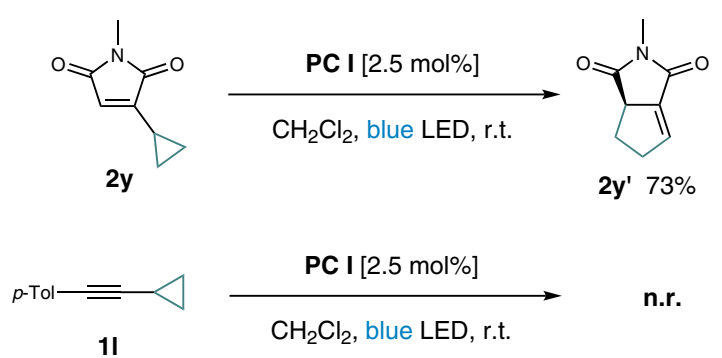

n.r.

Fig. $\mathbf{6}$ Radical clock experiments. Racemates for all products. a Intermolecular reaction between cyclopropyl alkyne $\mathbf{1}$ and $\mathbf{2 a}$. $\mathbf{b}$ Intermolecular reaction between $\mathbf{1 a}$ and cyclopropyl alkene $\mathbf{2 y}$. $\mathbf{c}$ Individual reactivity of $\mathbf{2 y}$ and $\mathbf{1}$ under the standard conditions. 
a

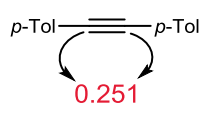

$1 \mathrm{a}$

$56.7 \mathrm{kcal} / \mathrm{mol}$

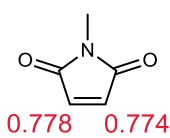

$2 \mathbf{a}$

$55.9 \mathrm{kcal} / \mathrm{mol}$

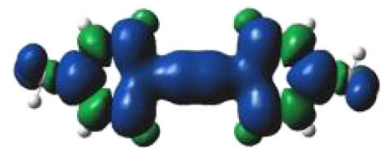

$1 \mathbf{a}$

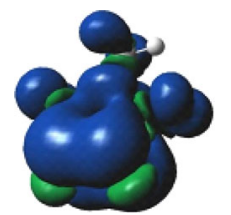

$2 a$

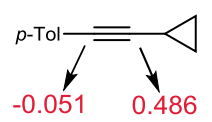

11

$63.9 \mathrm{kcal} / \mathrm{mol}$

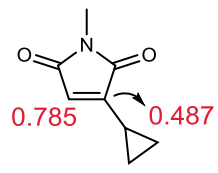

2y

b<smiles>O=C1C=CC(=O)N1C1CCCCC1</smiles>

$0.770 \quad 0.770$

2i

$56.2 \mathrm{kcal} / \mathrm{mol}$

$\left(80 \%{ }^{a}\right)$<smiles>N#Cc1ccc(N2C(=O)C=C([Se][Ba])C2=O)cc1</smiles>

$\left(59 \%{ }^{a}\right)$

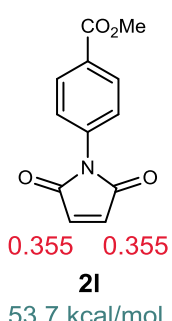

$\left(46 \%^{a}\right)$

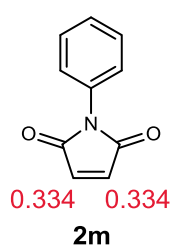

$50.4 \mathrm{kcal} / \mathrm{mol}$

$\left(29 \%{ }^{a}\right)$
$49.5 \mathrm{kcal} / \mathrm{mol}$

Fig. 7 Mulliken spin densities $\left(\mathbf{T}_{\mathbf{1}}\right)$ and triplet-singlet energy gaps of selected substrates. ${ }^{a}$ Reactions were conducted with the standard condition using di( $p$-tolyl)acetylene $\mathbf{1 a}(0.1 \mathrm{mmol})$. a Spin densities and surfaces of $\mathbf{1 a}$ and $\mathbf{2 a}$; Spin densities of cyclopropyl derivatives $\mathbf{1 1}$ and $\mathbf{2 y}$. $\mathbf{b}$ Correlation of spin densities and reaction efficiencies of $\mathrm{N}$-substituted maleimides.

$\left(E_{\mathrm{T}}=74.1 \mathrm{kcal} / \mathrm{mol}\right)$ than that of $\mathbf{P C} \mathbf{I}$, and yet the reaction with 2a provides cyclobutene $3 \mathrm{ma}$ in $56 \%$ (Fig. 5b), which leaves only one possibility of the participation of the triplet alkene.

To further support the rationale, we performed radical clock experiments (Fig. 6). Thus, alkyne $\mathbf{1 1}$ and maleimide $\mathbf{2 y}$ bearing a cyclopropyl group were prepared, and each of the substrates was reacted with $\mathbf{2 a}$ and $1 \mathrm{a}$, respectively (Fig. 6a, b). Whereas the reaction of cyclopropyl alkyne $\mathbf{1 1}$ with maleimide $\mathbf{2 a}$ proceeded to give the corresponding cycloadduct 3la in $67 \%$ yield, the formation of the isomerization product $2 \mathbf{y}^{\prime}$ along with cycloadduct 3ay was obtained in low yields when cyclopropyl maleimide $\mathbf{2 y}$ was reacted with alkyne 1a. Furthermore, when cyclopropyl maleimide $\mathbf{2 y}$ alone was subjected to the reaction conditions, $2 \mathbf{y}^{\prime}$ was obtained in $73 \%$ yield (Fig. 6c). On the other hand, cyclopropyl alkyne $\mathbf{1 1}$ was fully recovered when subjected to the conditions. These results that $2 \mathrm{y}$ undergoes ring opening upon excitation while $\mathbf{1 1}$ in its triplet state remains intact could be reasoned by the lack of the radical characters at the a-cyclopropylsubstitued carbon in the triplet state 11. (It was reported that the rate constant for the ring opening of $\alpha$-(2-phenylcyclopropyl)vinyl radicals is substantially higher than that of the corresponding $\alpha$ (2-phenylcyclopropyl)carbinyl radical $\left((1.6 \pm 0.2) \times 10^{10} \mathrm{~s}^{-1}\right.$ and $9.4 \times 10^{7} \mathrm{~s}^{-1}$, respectively) $)^{63,64}$.

To address the question, we performed DFT calculations on Mulliken spin density distributions (Fig. 7a). Whereas significantly low spin densities on the $s p$ carbons of alkynes 1a $(0.251$ and 0.251$)$ and 11 ( -0.051 and 0.486$)$ were observed, maleimides $2 a$ and $2 y$ showed much more localized spin densities on the carbons undergoing bond formation $(0.778$ and $0.774,0.785$ and 0.487 , respectively).

Moreover, during the survey for the scope of maleimides, we observed a wide spread in yields depending on the N-substitution. This prompted us to gauge the correlation between spin density

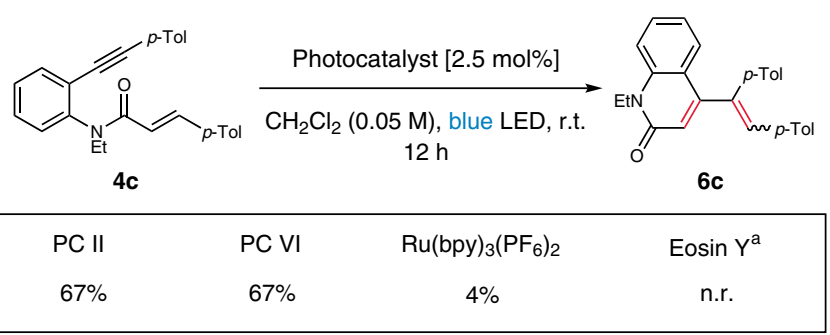

Fig. 8 Comparison of selected photocatalysts. Reactions were performed with $0.025 \mathrm{mmol}$ scale under Ar. Yields determined by ${ }^{1} \mathrm{H}$ NMR spectroscopic analysis against an internal standard. (1,1,2-trichloroethene). a Green LED was used instead of blue LED.

and reaction efficiency (Fig. 7b). A clear correlation was observed; generally, $\mathrm{N}$-aryl maleimides gave lower yields compared to $\mathrm{N}$ alkyl maleimides, for which the low spin density on the olefinic carbons appears to be responsible. On the other hand, maleimides substituted with electron-deficient aryl groups afforded higher yields, which is also consistent with their spin densities. Based on these experimental and computational studies, we propose that although both alkynes and alkenes undergo triplet excitation, the excited state alkenes react with the ground state alkynes to give the cycloadducts.

To examine whether the intramolecular reaction also proceeds via EnT mechanism, we performed a comparison with several photocatalysts. PC II and VI were chosen based on their triplet energies that are similar to or higher than that of $4 \mathrm{c}(49.0 \mathrm{kcal} /$ $\mathrm{mol})$. As a control, those with lower triplet energies, $\mathrm{Ru}$ $(\text { bpy })_{3}\left(\mathrm{PF}_{6}\right)_{2}$ and Eosin $\mathrm{Y}$, were also included. As shown in Fig. 8, the results were consistent with the triplet energies of the catalysts. Moreover, it is noteworthy that PC VI, which was ineffective in 
a

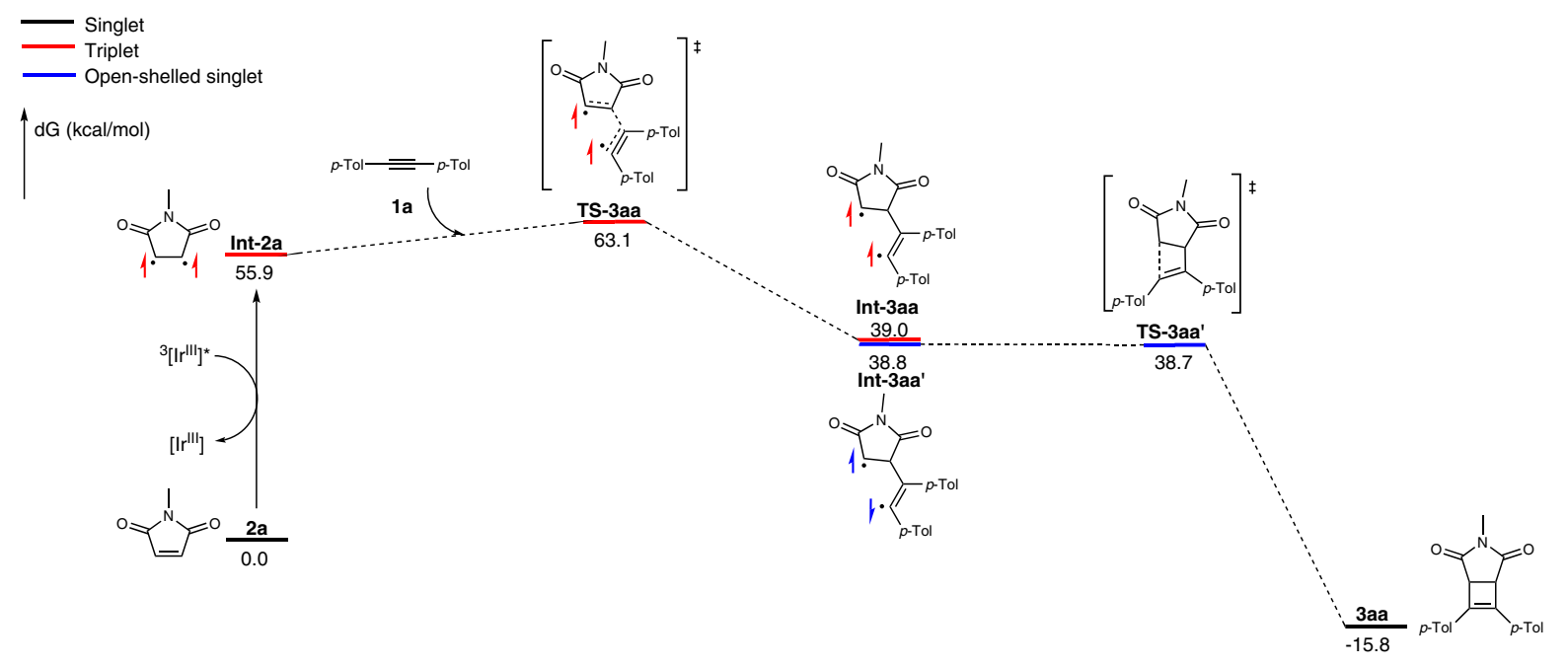

b

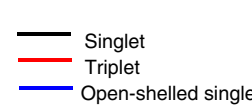

d dG (kcal/mol)
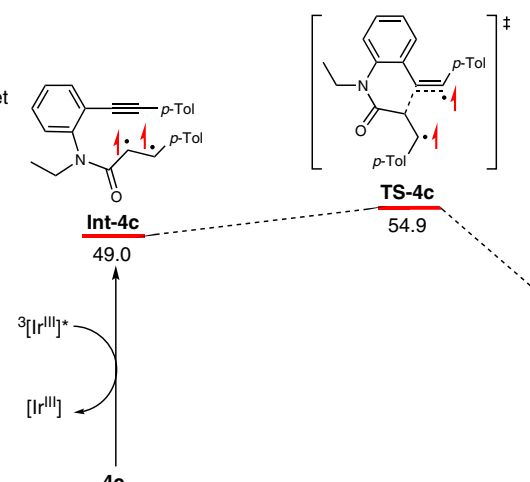

$\frac{\mathrm{TS}-4 \mathrm{C}}{54.9}$
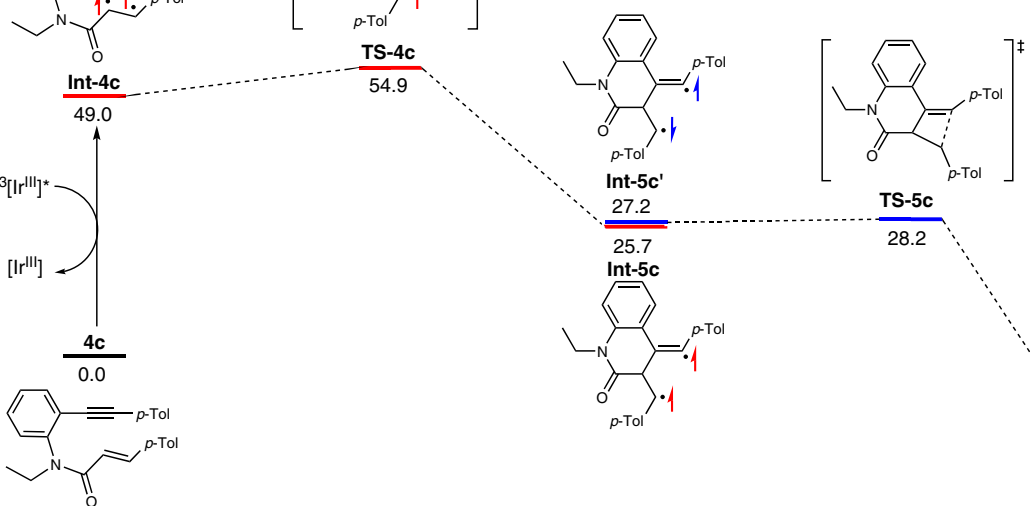

$\because 27.2$
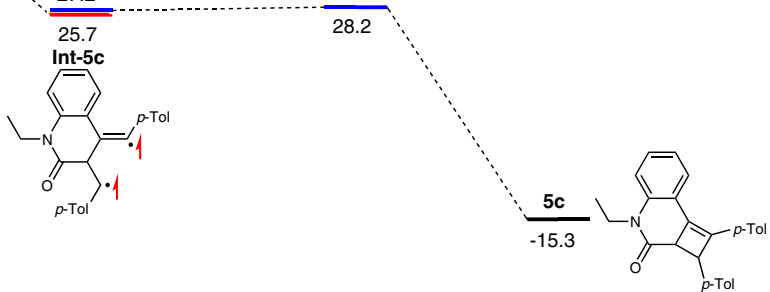

c

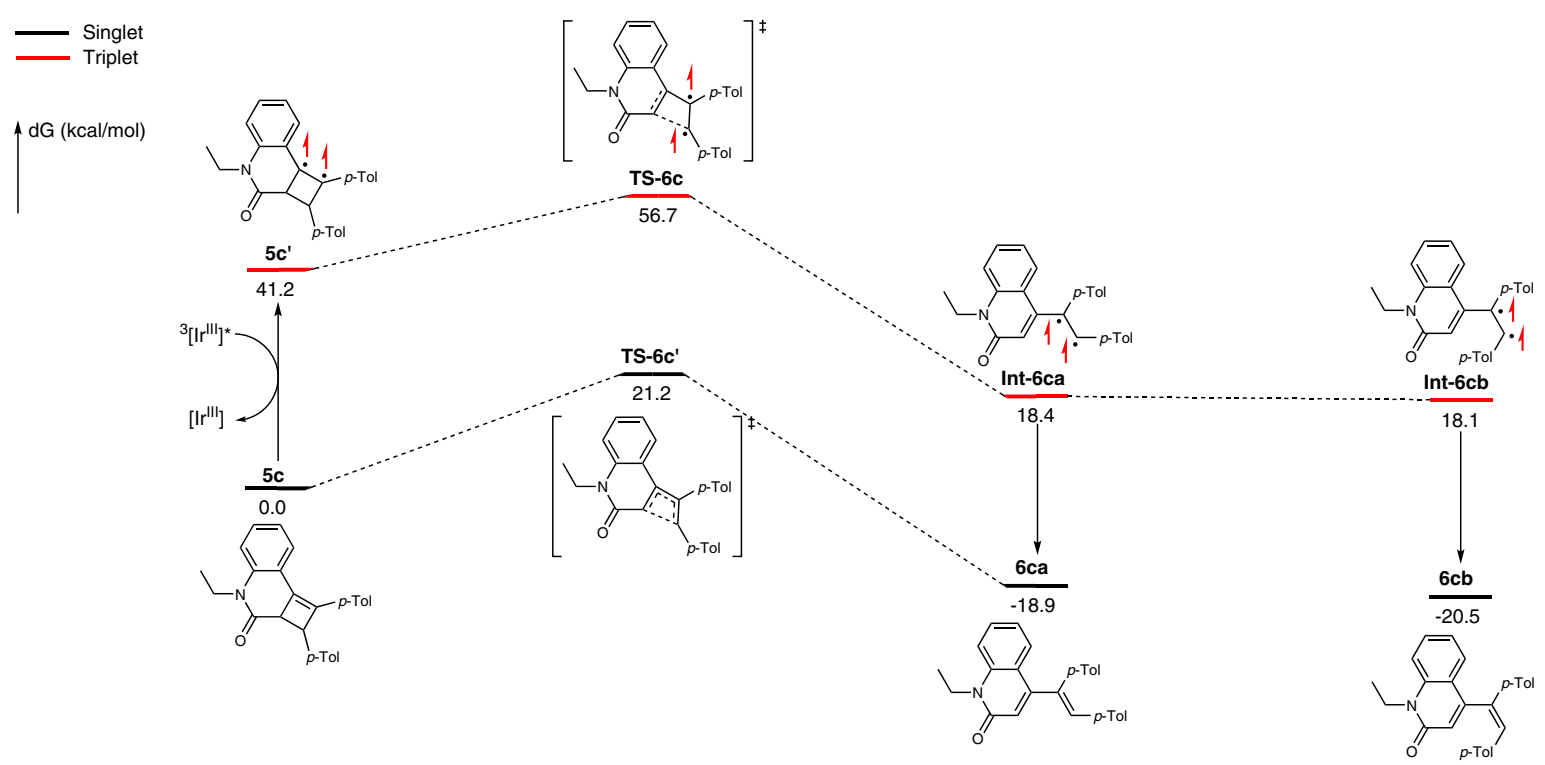

Fig. 9 DFT calculations. a Intermolecular cycloaddition between alkyne $\mathbf{1 a}$ and maleimide $\mathbf{2 a}$. b Formation of putative cyclobutene intermediate $\mathbf{5 c}$ from the intramolecular reaction of $\mathbf{4 c}$. c Formation of 1,3-dienes from $\mathbf{5 c}$. 
the intermolecular reaction owing to the low triplet level relative to the maleimide $(55.9 \mathrm{kcal} / \mathrm{mol})$, provided $6 \mathrm{c}$ in $67 \%$. Also, we investigated the redox property of $4 \mathrm{c}$ with cyclic voltammetry (see Supplementary Fig. 11$)$, the low reduction potential $\left(E_{\mathrm{p} / 2}{ }^{\text {red }}=\right.$ $-2.13,-2.44 \mathrm{~V}$ vs SCE) of which makes it unlikely to undergo reduction by the catalysts examined. Likewise, oxidative pathway could be ruled out based on the oxidation potentials of the catalysts. These results indicate that EnT mechanism is responsible for the intramolecular cycloaddition.

To shed light on the reaction pathway, we performed DFT calculations on the intermolecular and intramolecular reaction pathways. All calculations were carried out with the Gaussian 09 software $^{65}$ using the M06 functional ${ }^{66}$ with the $6-311+\mathrm{g}(\mathrm{d}, \mathrm{p})$ basis set ${ }^{67,68}$. The SMD solvation model ${ }^{69}$ with the solvent of dichloromethane $(\varepsilon=8.93)$ was used for all calculations. The DFT calculations on the intermolecular cycloaddition between alkyne 1a and maleimide $2 \mathbf{a}$ revealed that excitation of $\mathbf{2 a}$ to its $\mathrm{T}_{1}$ state $(55.9 \mathrm{kcal} / \mathrm{mol})$ by the catalyst followed by the reaction with alkyne 1a leads to the formation of the triplet intermediate Int3aa via TS-3aa $\left(\Delta G^{\ddagger}=7.2 \mathrm{kcal} / \mathrm{mol}\right)$ (Fig. 9a). Subsequently, conversion to open-shell singlet state Int-3aa' allows the formation of cyclobutene 3aa via barrierless TS-3aa'. On the other hand, we were intrigued by the formation of 1,3-dienes instead of cyclobutenes from the intramolecular reaction. Our hypothesis was that tandem triplet activation of the initial cyclobutenes may account for the formation of 1,3-dienes. Thus, we performed DFT calculations on the reaction pathway involving the formation of 1,3-dienes via cyclobutenes as intermediates, and compared the activation barrier with that of thermal electrocyclic ring opening (Fig. 9b, c). The formation of cyclobutene $5 \mathrm{c}$ is initiated by the excitation of $4 \mathrm{c}$ to its triplet state $(49.0 \mathrm{kcal} / \mathrm{mol})$ by the catalyst. The addition to the alkyne to form triplet diradical Int-5c via TS-4c $\left(\Delta \mathrm{G}^{\ddagger}=5.9 \mathrm{kcal} / \mathrm{mol}\right)$ followed by conversion to the open-shell singlet state Int-5 $\mathbf{c}^{\prime}$ via barrierless TS-5c results in the formation of cyclobutene $\mathbf{5 c}$.

It turns out that cyclobutene $\mathbf{5 c}$ could be readily excited to its $\mathrm{T}_{1}$ state $(41.2 \mathrm{kcal} / \mathrm{mol})$ by the catalyst $\left(60.8 \mathrm{kcal} / \mathrm{mol}\right.$ for $\mathrm{T}_{1}$ state $)$ (Fig. 9c). Rearrangement of the triplet diradical affords Int$\mathbf{6 c a} / \mathbf{6 c b}$ with the activation barrier of $15.5 \mathrm{kcal} / \mathrm{mol}$, which results in the formation of diene $\mathbf{6} \mathbf{c a} / \mathbf{6} \mathbf{c b}$. In comparison, the activation barrier of the thermal electrocyclic ring opening via TS-6c' turned out to be significantly higher $(21.2 \mathrm{kcal} / \mathrm{mol})$. These results are in contrast to the cyclobutenes derived from intermolecular cycloaddition, in which a significantly higher $\Delta \mathrm{G}^{\ddagger}(29.5 \mathrm{kcal} /$ $\mathrm{mol}$ ) appears to be responsible for interrupting ring opening (see Supplementary Fig. 12).

\section{Discussion}

We developed alkyne-alkene [2+2] cycloaddition based on visible light EnT photocatalysis. Whereas the formation of cyclobutenes was observed from intermolecular reactions, 1,3dienes were obtained from intramolecular reactions. For the intermolecular cycloaddition, a broad range of alkynes reacted smoothly with electron-deficient alkenes to afford the corresponding cyclobutenes. On the other hand, for the 1,3-diene formation in the intramolecular reactions, the ring opening of cyclobutene intermediates via tandem triplet excitation is responsible. Synthetically, the $[2+2]$ enyne cycloaddition offers a complementary means to the $\mathrm{Ru}(\mathrm{II})$-catalyzed enyne metathesis for the synthesis of highly substituted 1,3-dienes. Various experimental evidences support that between the two reactants, alkyne and alkene, the alkene undergoes productive excitation to a triplet state to react with the ground state alkyne. We also demonstrated the utility of the method including the synthesis of various extended $\pi$-system.

\section{Methods}

General procedure for the synthesis of cyclobutenes. Alkyne $(0.1 \mathrm{mmol}, 1.0$ equiv.), alkene (1.5 equiv.), and photocatalyst $\operatorname{Ir}\left[\mathrm{dF}\left(\mathrm{CF}_{3}\right) \mathrm{ppy}\right]_{2}(\mathrm{dtbbpy}) \mathrm{PF}_{6}(\mathbf{P C} \mathbf{I}$, $2.5 \mathrm{~mol} \%$ ) were added to an oven-dried $4 \mathrm{~mL}$ vial equipped with a stir bar. The combined materials were dissolved in $\mathrm{CH}_{2} \mathrm{Cl}_{2}(2 \mathrm{~mL})$ under argon atmosphere in glovebox. The reaction mixture was then irradiated by $12 \mathrm{~W}$ blue LED strip at room temperature (maintained with a cooling fan). After completion of the reaction as indicated by TLC, the solution was concentrated under reduced pressure. The residue was purified by flash column chromatography on silica gel to give the desired product. See Supplementary Methods for further experimental details.

\section{Data availability}

The authors declare that all the data supporting the findings of this study are available within the paper and its Supplementary Information files, or from the corresponding author upon request.

Received: 19 October 2019; Accepted: 22 April 2020; Published online: 19 May 2020

\section{References}

1. Misale, A., Niyomchon, S. \& Maulide, N. Cyclobutenes: at a crossroad between diastereoselective syntheses of dienes and unique palladium-catalyzed asymmetric allylic substitutions. Acc. Chem. Res. 49, 2444-2458 (2016).

2. Donnelly, B. L., Elliott, L. D., Willis, C. L. \& Booker-Milburn, K. I. Sequential photochemical and prins reactions for the diastereoselective synthesis of tricyclic scaffolds. Angew. Chem. Int. Ed. 58, 9095-9098 (2019).

3. Kokubo, K., Yamaguchi, H., Kawamoto, T. \& Oshima, T. Substituent effects on the stereochemistry in the $[2+2]$ photocycloaddition reaction of homobenzoquinone derivative with variously substituted alkenes and alkynes. J. Am. Chem. Soc. 124, 8912-8921 (2002).

4. Zeidan, T. A. et al. Triplet acetylenes as synthetic equivalents of 1,2bicarbenes: phantom $n, \pi^{*}$ state controls reactivity in triplet photocycloaddition. J. Am. Chem. Soc. 127, 4270-4285 (2005).

5. Winkler, J. D. \& McLaughlin, E. C. Intramolecular photocycloaddition of dioxenones with alkynes: formation of secondary photoproducts from cyclobutene photoadducts. Org. Lett. 7, 227-229 (2005).

6. Booker-Milburn, K. I., Cowell, J. K., Delgado Jiménez, F., Sharpe, A. \& White, A. J. Stereoselective intermolecular $[2+2]$ photocycloaddition reactions of tetrahydrophthalic anhydride and derivatives with alkenols and alkynols. Tetrahedron 55, 5875-5888 (1999).

7. Maturi, M. M. \& Bach, T. Enantioselective catalysis of the intermolecular $[2+$ 2] photocycloaddition between 2-pyridones and acetylenedicarboxylates. Angew. Chem. Int. Ed. 53, 7661-7664 (2014).

8. Shen, L. et al. Lewis acid-catalyzed selective $[2+2]$-cycloaddition and dearomatizing cascade reaction of aryl alkynes with acrylates. J. Am. Chem. Soc. 139, 13570-13578 (2017).

9. Peng, C. et al. Lewis acids catalyzed annulations of ynamides with acyl chlorides for constructing 4-amino-2-naphthol derivatives and 3aminocyclobutenones. J. Org. Chem. 83, 9256-9266 (2018).

10. Atkin, L. et al. Synthesis of alkyl citrates (-)-CJ-13,981, (-)-CJ-13,982, and (-)-L-731,120 via a cyclobutene diester. Org. Lett. 20, 4255-4258 (2018).

11. Pradhan, T. R., Kim, H. W. \& Park, J. K. Harnessing the polarizability of conjugated alkynes toward $[2+2]$ cycloaddition, alkenylation, and ring expansion of indoles. Org. Lett. 20, 5286-5290 (2018).

12. Iwai, T., Ueno, M., Okochi, H. \& Sawamura, M. Synthesis of cyclobutenefused eight-membered carbocycles through gold-catalyzed intramolecular enyne [2+2] cycloaddition. Adv. Synth. Catal. 360, 670-675 (2018).

13. Kossler, D. \& Cramer, N. Neutral chiral cyclopentadienyl $\mathrm{Ru}(\mathrm{ii}) \mathrm{Cl}$ catalysts enable enantioselective [2+2]-cycloadditions. Chem. Sci. 8, 1862-1866 (2017).

14. Bai, Y. B., Luo, Z., Wang, Y., Gao, J. M. \& Zhang, L. Au-catalyzed intermolecular $[2+2]$ cycloadditions between chloroalkynes and unactivated alkenes. J. Am. Chem. Soc. 140, 5860-5865 (2018).

15. Nishimura, A., Ohashi, M. \& Ogoshi, S. Nickel-catalyzed intermolecular $[2+$ 2] cycloaddition of conjugated enynes with alkenes. J. Am. Chem. Soc. 134, 15692-15695 (2012).

16. Pagar, V. V. \& RajanBabu, T. V. Tandem catalysis for asymmetric coupling of ethylene and enynes to functionalized cyclobutanes. Science 361, 68-72 (2018).

17. Chen, J. R., Hu, X. Q., Lu, L. Q. \& Xiao, W. J. Exploration of visible-light photocatalysis in heterocycle synthesis and functionalization: reaction design and beyond. Acc. Chem. Res. 49, 1911-1923 (2016).

18. Prier, C. K., Rankic, D. A. \& MacMillan, D. W. Visible light photoredox catalysis with transition metal complexes: applications in organic synthesis. Chem. Rev. 113, 5322-5363 (2013). 
19. Skubi, K. L., Blum, T. R. \& Yoon, T. P. Dual catalysis strategies in photochemical synthesis. Chem. Rev. 116, 10035-10074 (2016).

20. Twilton, J. et al. The merger of transition metal and photocatalysis. Nat. Rev. Chem. 1, 1-18 (2017).

21. Jin, J. \& MacMillan, D. W. Direct alpha-arylation of ethers through the combination of photoredox-mediated C-H functionalization and the Minisci reaction. Angew. Chem. Int. Ed. 54, 1565-1569 (2015).

22. Hossain, A. et al. Visible-light-accelerated copper(II)-catalyzed regio- and chemoselective oxo-azidation of vinyl arenes. Angew. Chem. Int. Ed. 57, 8288-8292 (2018).

23. $\mathrm{Hu}, \mathrm{X}$.-Q. et al. Photocatalytic generation of N-centered hydrazonyl radicals: a strategy for hydroamination of $\beta, \gamma$-unsaturated hydrazones. Angew. Chem. Int. Ed. 53, 12163-12167 (2014).

24. Huang, X., Webster, R. D., Harms, K. \& Meggers, E. Asymmetric catalysis with organic azides and diazo compounds initiated by photoinduced electron transfer. J. Am. Chem. Soc. 138, 12636-12642 (2016).

25. Matier, C. D., Schwaben, J., Peters, J. C. \& Fu, G. C. Copper-catalyzed alkylation of aliphatic amines induced by visible light. J. Am. Chem. Soc. 139, 17707-17710 (2017).

26. Shimomaki, K., Murata, K., Martin, R. \& Iwasawa, N. Visible-light-driven carboxylation of aryl halides by the combined use of palladium and photoredox catalysts. J. Am. Chem. Soc. 139, 9467-9470 (2017).

27. Zhou, Q.-Q., Zou, Y.-Q., Lu, L.-Q. \& Xiao, W.-J. Visible-light-induced organic photochemical reactions through energy-transfer pathways. Angew. Chem. Int. Ed. 58, 1586-1604 (2019).

28. Strieth-Kalthoff, F., James, M. J., Teders, M., Pitzer, L. \& Glorius, F. Energy transfer catalysis mediated by visible light: principles, applications, directions. Chem. Soc. Rev. 47, 7190-7202 (2018).

29. Higgins, R. F. et al. Detection of an energy-transfer pathway in Cr-photoredox catalysis. ACS Catal. 8, 9216-9225 (2018).

30. Xia, X.-D. et al. Synthesis of 2-substituted indoles through visible lightinduced photocatalytic cyclizations of styryl azides. Adv. Synth. Catal. 356, 2807-2812 (2014).

31. Farney, E. P. \& Yoon, T. P. Visible-light sensitization of vinyl azides by transition-metal photocatalysis. Angew. Chem. Int. Ed. 53, 793-797 (2014)

32. Xuan, J. et al. Visible-light-induced formal [3+2] cycloaddition for pyrrole synthesis under metal-free conditions. Angew. Chem. Int. Ed. 53, 5653-5656 (2014).

33. Scholz, S. O., Farney, E. P., Kim, S., Bates, D. M. \& Yoon, T. P. Spin-selective generation of triplet nitrenes: olefin aziridination through visible-light photosensitization of azidoformates. Angew. Chem. Int. Ed. 55, 2239-2242 (2016).

34. Brachet, E., Ghosh, T., Ghosh, I. \& König, B. Visible light C-H amidation of heteroarenes with benzoyl azides. Chem. Sci. 6, 987-992 (2015).

35. Huang, $X$. et al. Catalytic asymmetric synthesis of a nitrogen heterocycle through stereocontrolled direct photoreaction from electronically excited state. Nat. Commun. 8, 2245-2245 (2017).

36. Molloy, J. J., Metternich, J. B., Daniliuc, C. G., Watson, A. J. B. \& Gilmour, R. Contra-thermodynamic, photocatalytic $\mathrm{E} \rightarrow \mathrm{Z}$ isomerization of styrenyl boron species: vectors to facilitate exploration of two-dimensional chemical space. Angew. Chem. Int. Ed. 57, 3168-3172 (2018).

37. Singh, A., Fennell, C. J. \& Weaver, J. D. Photocatalyst size controls electron and energy transfer: selectable $\mathrm{E} / \mathrm{Z}$ isomer synthesis via $\mathrm{C}-\mathrm{F}$ alkenylation. Chem. Sci. 7, 6796-6802 (2016).

38. Rackl, D., Kreitmeier, P. \& Reiser, O. Synthesis of a polyisobutylene-tagged fac-Ir(ppy)3 complex and its application as recyclable visible-light photocatalyst in a continuous flow process. Green. Chem. 18, 214-219 (2016).

39. Lei, T. et al. General and efficient intermolecular $[2+2]$ photodimerization of chalcones and cinnamic acid derivatives in solution through visible-light catalysis. Angew. Chem. Int. Ed. 56, 15407-15410 (2017).

40. Hörmann, F. M., Chung, T. S., Rodriguez, E., Jakob, M. \& Bach, T. Evidence for triplet sensitization in the visible-light-induced $[2+2]$ photocycloaddition of eniminium ions. Angew. Chem. Int. Ed. 57, 827-831 (2018).

41. Kumarasamy, E., Raghunathan, R., Jockusch, S., Ugrinov, A. \& Sivaguru, J. Tailoring atropisomeric maleimides for stereospecific $[2+2]$ photocycloaddition-photochemical and photophysical investigations leading to visible-light photocatalysis. J. Am. Chem. Soc. 136, 8729-8737 (2014).

42. Skubi, K. L. et al. Enantioselective excited-state photoreactions controlled by a chiral hydrogen-bonding iridium sensitizer. J. Am. Chem. Soc. 139, 17186-17192 (2017).

43. Ahuja, S., Raghunathan, R., Kumarasamy, E., Jockusch, S. \& Sivaguru, J. Realizing the photoene reaction with alkenes under visible light irradiation and bypassing the favored [2+2]-photocycloaddition. J. Am. Chem. Soc. 140, 13185-13189 (2018).

44. Zhu, M., Zheng, C., Zhang, X. \& You, S. L. Synthesis of cyclobutane-fused angular tetracyclic spiroindolines via visible-light-promoted intramolecular dearomatization of indole derivatives. J. Am. Chem. Soc. 141, 2636-2644 (2019).
45. James, M. J., Schwarz, J. L., Strieth-Kalthoff, F., Wibbeling, B. \& Glorius, F. Dearomative cascade photocatalysis: divergent synthesis through catalyst selective energy transfer. J. Am. Chem. Soc. 140, 8624-8628 (2018).

46. Blum, T. R., Miller, Z. D., Bates, D. M., Guzei, I. A. \& Yoon, T. P. Enantioselective photochemistry through Lewis acid-catalyzed triplet energy transfer. Science 354, 1391-1395 (2016).

47. Strieth-Kalthoff, F. et al. Discovery of unforeseen energy-transfer-based transformations using a combined screening approach. Chem 5, 2183-2194 (2019).

48. Lanzi, M. et al. Visible-light-promoted polycyclizations of dienynes. Angew. Chem. Int. Ed. 58, 6703-6707 (2019).

49. Nieto-Oberhuber, C. et al. Divergent mechanisms for the skeletal rearrangement and $[2+2]$ cycloaddition of enynes catalyzed by gold. Angew. Chem. Int. Ed. 44, 6146-6148 (2005).

50. Witham, C. A., Mauleón, P., Shapiro, N. D., Sherry, B. D. \& Toste, F. D. Gold (I)-catalyzed oxidative rearrangements. J. Am. Chem. Soc. 129, 5838-5839 (2007).

51. Mézailles, N., Ricard, L. \& Gagosz, F. Phosphine gold(I) bis(trifluoromethanesulfonyl)imidate complexes as new highly efficient and airstable catalysts for the cycloisomerization of enynes. Org. Lett. 7, 4133-4136 (2005).

52. Bartholomeyzik, T. et al. Kinetics and mechanism of the palladium-catalyzed oxidative arylating carbocyclization of allenynes. J. Am. Chem. Soc. 140 298-309 (2018).

53. Li, M.-B. et al. Chemodivergent and diastereoselective synthesis of gammalactones and gamma-lactams: a heterogeneous palladium-catalyzed oxidative tandem process. J. Am. Chem. Soc. 140, 14604-14608 (2018).

54. Fürstner, A., Stelzer, F. \& Szillat, H. Platinum-catalyzed cycloisomerization reactions of enynes. J. Am. Chem. Soc. 123, 11863-11869 (2001).

55. Fürstner, A., Szillat, H. \& Stelzer, F. Novel rearrangements of enynes catalyzed by $\mathrm{PtCl}_{2}$. J. Am. Chem. Soc. 122, 6785-6786 (2000).

56. Nicolaou, K. C., Bulger, P. G. \& Sarlah, D. Metathesis reactions in total synthesis. Angew. Chem. Int. Ed. 44, 4490-4527 (2005).

57. Prada Gori, D. N., Permingeat Squizatto, C., Cornier, P. G. \& Delpiccolo, C M. L. Design of a selective ring-closing enyne metathesis-reduction for the generation of different synthetic scaffolds. J. Org. Chem. 83, 12798-12805 (2018).

58. Cabrele, C. \& Reiser, O. The modern face of synthetic heterocyclic chemistry. J. Org. Chem. 81, 10109-10125 (2016).

59. Allard, S., Forster, M., Souharce, B., Thiem, H. \& Scherf, U. Organic semiconductors for solution-processable field-effect transistors (OFETs) Angew. Chem. Int. Ed. 47, 4070-4098 (2008).

60. Shanmugaraju, S. \& Mukherjee, P. S. $\pi$-Electron rich small molecule sensors for the recognition of nitroaromatics. Chem. Commun. 51, 16014-16032 (2015).

61. Cao, D. et al. Coumarin-based small-molecule fluorescent chemosensors. Chem. Rev. 119, 10403-10519 (2019).

62. Tasior, M. et al. $\pi$-Expanded coumarins: synthesis, optical properties and applications. J. Mater. Chem. C. 3, 1421-1446 (2015).

63. Milnes, K. K., Gottschling, S. E. \& Baines, K. M. Determination of the rate constant for ring opening of an alpha-cyclopropylvinyl radical. Org. Biomol. Chem. 2, 3530-3534 (2004).

64. Mainetti, E., Fensterbank, L. \& Malacria, M. New elements in the reactivity of a-cyclopropyl vinyl radicals. Synlett 2002, 923-926 (2002).

65. Frisch, M. J., et al. Gaussian 09, Revision D.01. (2013).

66. Zhao, Y. \& Truhlar, D. G. The M06 suite of density functionals for main group thermochemistry, thermochemical kinetics, noncovalent interactions, excited states, and transition elements: two new functionals and systematic testing of four M06-class functionals and 12 other functionals. Theor. Chem. Acc. 120 215-241 (2008).

67. Krishnan, R., Binkley, J. S., Seeger, R. \& Pople, J. A. Self-consistent molecular orbital methods. XX. A basis set for correlated wave functions. J. Chem. Phys. 72, 650-654 (1980).

68. Clark, T., Chandrasekhar, J., Spitznagel, G. W. \& Schleyer, P. V. R. Efficient diffuse function-augmented basis sets for anion calculations. III. The 3-21+G basis set for first-row elements, Li-F. J. Comput. Chem. 4, 294-301 (1983).

69. Marenich, A. V., Cramer, C. J. \& Truhlar, D. G. Universal solvation model based on solute electron density and on a continuum model of the solvent defined by the bulk dielectric constant and atomic surface tensions. J. Phys. Chem. B 113, 6378-6396 (2009).

\section{Acknowledgements}

This work was supported by the National Research Foundation of Korea (NRF) grants (2014R1A5A1011165 Center for New Directions in Organic Synthesis (CNOS), NRF 2017R1A2B2012946, NRF 2017M3A9E4078558) funded by the Korean government and the UNIST Research Fund (1.170096.01). 


\section{Author contributions}

C.M.P. conceived the project. S.H. and C.-M.P. designed experiments and cowrote the paper. S.H., Y.L., Y.K., A.M., and B.R. performed experiments. E.Y. performed DFT calculations.

\section{Competing interests}

The authors declare no competing interests.

\section{Additional information}

Supplementary information is available for this paper at https://doi.org/10.1038/s41467020-16283-9.

Correspondence and requests for materials should be addressed to C.-M.P.

Peer review information Nature Communications thanks the anonymous reviewer(s) for their contribution to the peer review of this work. Peer reviewer reports are available.

Reprints and permission information is available at http://www.nature.com/reprints
Publisher's note Springer Nature remains neutral with regard to jurisdictional claims in published maps and institutional affiliations.

(c) (i) Open Access This article is licensed under a Creative Commons Attribution 4.0 International License, which permits use, sharing, adaptation, distribution and reproduction in any medium or format, as long as you give appropriate credit to the original author(s) and the source, provide a link to the Creative Commons license, and indicate if changes were made. The images or other third party material in this article are included in the article's Creative Commons license, unless indicated otherwise in a credit line to the material. If material is not included in the article's Creative Commons license and your intended use is not permitted by statutory regulation or exceeds the permitted use, you will need to obtain permission directly from the copyright holder. To view a copy of this license, visit http://creativecommons.org/ licenses/by/4.0/.

(C) The Author(s) 2020 